\title{
Polymorphisms in RAS Guanyl-releasing Protein 3 are Associated with Chronic Liver Disease and Hepatocellular Carcinoma in a Korean Population
}

\begin{abstract}
Ah-Reum $\mathrm{Oh}^{1}$, Seung Ku Lee ${ }^{1}$, Min-Ho Kim', Jae Youn Cheong', Sung Won $\mathrm{Cho}^{2}$, KapSeok Yang $^{3}$ and KyuBum Kwack ${ }^{1 *}$

${ }^{1}$ Medical Genomics Laboratory, Graduate School of Life Science and Biotechnology, Pochon CHA University, Seongnam 463-836, Korea, ${ }^{2}$ Department of Gastroenterology, Genomic Research Center for Gastroenterology, Ajou University School of Medicine, Suwon 442-721, Korea, ${ }^{3}$ Macrogen Inc. 60-24, Seoul 153-781, Korea
\end{abstract}

\begin{abstract}
RAS guanyl-releasing protein 3 (RasGRP3), a member of the Ras subfamily of GTPases, functions as a guanosine triphosphate (GTP)/guanosine diphosphate (GDP)-regulated switch that cycles between inactive GDP- and active GTP-bound states during signal transduction. Various growth factors enhance hepatocellular carcinoma (HCC) proliferation via activation of the Ras/Raf-1/ extracellular signal-regulated kinase (ERK) pathway, which depends on RasGRP3 activation. We investigated the relationship between polymorphisms in RasGRP3 and progression of hepatitis B virus (HBV)-infected HCC in a Korean population. Nineteen RasGRP3 SNPs were genotyped in 206 patients with chronic liver disease (CLD) and 86 patients with HCC. Our results revealed that the T allele of the rs7597095 SNP and the C allele of the rs7592762 SNP increased susceptibility to HCC $(\mathrm{OR}=1.55, \mathrm{p}=0.04$ and $\mathrm{OR}=1.81 \sim 2.61, \mathrm{p}=0.01 \sim 0.03$, respectively). Moreover, patients who possessed the haplotype (ht) 1 (A-T-C-G) or diplotype (dt) 1 (ht1/ht/) variations had increased susceptibility to HCC (OR=1.79 $\sim 2.78, p=0.01 \sim 0.03$ ). In addition, we identified an association between haplotype1 (ht1) and the age of HCC onset; the age of HCC onset are earlier in ht $1+/+$ than ht1 +/- or ht1 -/- (HR=0.42 0.66, $p=0.006 \sim 0.015)$. Thus, our data suggest that RasGRP3 SNPs are significantly associated with an increased risk of developing HCC.
\end{abstract}

Keywords: chronic liver disease (CLD), hepatocellular

*Corresponding author: E-mail kbkwack@cha.ac.kr, kbkwack@gmail.com

Tel +82-31-725-8376, Fax +82-31-725-8350

Accepted 15 November 2008 carcinoma $(\mathrm{HCC})$, hepatitis $B$ virus $(\mathrm{HBV})$, phospholipase C gamma 1, single nucleotide polymorphism (SNP)

\section{Introduction}

Hepatocellular carcinoma (HCC) is the fifth-most prevalent cancer worldwide and the third-most lethal malignancy (Bosch, Ribes et al., 2004; Bruix, Boix et al., 2004). On average, approximately 398,000 males are diagnosed with HCC each year in the world (Parkin, Bray et al., 2001). It is well known that hepatitis B virus (HBV), hepatitis C virus ( $\mathrm{HCV})$, aflatoxin B1 intake, and metabolic disorders such as hemochromatiosis and alpha-antitrypsin deficiency are major risk factors for liver cirrhosis and HCC (Arbuthnot and Kew, 2001). The incidence of HCC that is coincident with HBV infection is high in East Asian and African countries (Caselmann, 1998). More than $90 \%$ of HCC tumors are found in patients with chronic hepatitis or cirrhosis (Laurent-Puig and Zucman-Rossi, 2006). Recent studies have compared healthy patients with those who suffer from liver disease (including chronic hepatitis, cirrhosis, and HCC). However, few studies have studied the progression of chronic liver disease with regard to HCC.

Genetic variations are thought to influence the risk of developing HCC (Edmondson, Henderson et al., 1976; Cha and Dematteo, 2005), particularly those that involve the activation of cellular oncogenes or the inactivation of tumor suppressor genes in various signaling pathways (e.g., mutation of beta-catenin-related Wnt/beta-catenin signals (Pang, Yuen et al., 2004) and overexpression of Ras signaling (Mitin, Rossman et al., 2005)). Also, single nucleotide polymorphsims (SNPs) of many famous genes, such as p53 (Kirk, Lesi et al., 2005), HDAC10 (Park, Kim et al., 2007) and MMP2 (Wu, Zhang et al., 2008), have been significantly associated with HCC. The significant SNPs of these genes may represent genetic markers that are in linkage disequilibrium (LD) with other causative variations. Also recently, many SNP studies that are related to various human diseases have been reported (Lee, Kim et al., 2007).

Ras signaling transduction pathways influence cell proliferation, survival, differentiation, vesicular trafficking, and gene expression in B cells (Mitin, Rossman et al., 2005). In previous studies, various growth factors were found to enhance HCC cell proliferation, as well as tu- 
mor invasion and metastasis, via the activation of the Ras/Raf-1/extracellular signal-regulated kinase (ERK) pathway (Nonomura, Ohta et al., 1987; Pang, Yuen et al., 2004; Tsuboi, Ichida et al., 2004). Also, overexpression of Ras genes is common in human HCC tissue. Active Ras stimulates the Raf1-Mek-1/ERK effectors by binding to RassF1A and appears to induce apoptosis (Ito, Sasaki et al., 1998). RassF1A hypermethylation has been observed in various cancer cell lines, including an HCC cell line (Schmidt, McKillop et al., 1997).

RasGRP3 (Ras guanyl-releasing protein 3) is a member of the Ras subfamily of GTPases as a guanosine diphosphate (GDP)/guanosine triphosphate (GTP) nucleotide exchange factor (GEF) and functions in signal transduction as a GTP/GDP-regulated switch that cycles between inactive GDP- and active GTP-bound states (Rebhun, Castro et al., 2000). These factors are key links between cell surface receptors and Ras activation. RasGRP3 is located from chromosomes 2p24.1 to p25.1 and comprises 19 exons. RasGRP3 consists of 4 domains that contain the Ras exchange motif (REM), a Ras-GEF domain, EF-hands and a C1 domain. The C1 domain of RasGRP3 binds directly to phorbol esters, acts as a potent tumor-promoting operator, and is expressed in skeletal muscle and liver (Lorenzo, Kung et al., 2001). In addition, the activation of RasGRP3 by Thr-133 phosphorylation induces the B cell receptor signaling and activates small GTPases of the Ras, Rho, and Ra1 families, which play important roles in tumor biology (Aiba, Oh-hora et al., 2004). RasGRP3 also is thought to be associated with developing blood vessels via its involvement in vascular endothelial growth factor (VEGF) signaling, which plays an important role in angiogenesis (Roberts, Anderson et al., 2004).

While RasGRP3 plays important roles in the regulation of Ras signaling, studies have not examined the polymorphisms that are present within this protein. Therefore, we explored RasGRP3 polymorphisms in a Korean population and explored the link between these polymorphisms and the risk of developing HCC during HBV infection.

\section{Methods}

\section{Subjects}

The study population contained a total of 302 patients, including 86 patients with HCC patients (i.e., cases) and 206 patients with CLD (i.e., controls). A total of 302 Korean subjects with present or past evidence of HBV infection were recruited from the Ajou Genomic Research Center for Gastroenterology at the Ajou
University Medical Center in Suwon, South Korea between March 2002 and February 2006. The study protocol was approved by the Institutional Review Boards (IRBs) of Ajou University Hospital and Pochon CHA University. Serological markers were identified using commercially available assays for hepatitis B surface antigen ( $\mathrm{HBs} A g)$, antibodies to hepatitis $B$ core antigen (Anti-HBc; HBcAb), antibodies to hepatitis B surface antigen (Anti-HBs; HBsAb), hepatitis $B$ ' $e$ ' antigen ( $\mathrm{HBeAg}$ ), antibodies to hepatitis $B$ ' $e$ ' antigen (Anti-HBe; $\mathrm{HBeAb}$ ), HBV-DNA, albumin, alpha-fetoprotein (AFP), glutamyl transpeptidase, platelets, aspartate aminotransferase (AST), alanine aminotransferase (ALT), bilirubin, cholesterol, total protein, and white blood cells. Patients were divided into 2 groups. The first group (i.e., $\mathrm{n}=206$ ) experienced CLD for more than 7 months without HCC. This group consisted of patients with chronic hepatitis and liver cirrhosis who were positive for $\mathrm{HBsAg}$ and negative for HBsAb (HBcAb $(+)$, HBeAg (+), or HBV-DNA $(+))$. Patients with chronic hepatitis exhibited elevated ALT levels (i.e., $\geq 2$ times the upper limit of normal) at least once during the follow-up period and were diagnosed via ultrasonography. The second group (i.e., $\mathrm{n}=86$ ) consisted of patients with HCC who tested positive for HBsAg and negative for HBsAb (HBcAb (+), HBeAg $(+)$, or HBV-DNA (+)). These patients were diagnosed using standard criteria (i.e., serum AFP levels greater than $400 \mathrm{ng} / \mathrm{ml}$ ) via ultrasonography, computed tomography (CT), or magnetic resonance imaging (MRI). Patients who tested positive for anti-HCV or anti-HIV antibodies were excluded from the analysis.

\section{Selection of SNPs in the RasGRP3 gene}

We selected the RasGRP3 gene, which regulates ras signaling; its signaling is important for carcinogenic mechanisms and is especially important for the development of hepatocellular carcinoma. The basic hypothesis that underlies our approach is that there is more than 1 common SNP in the genes of interest that are associated with an altered risk of HCC. To identify a set of tagging SNPs (tSNPs), that efficiently tags all the known common variants (MAF; minor allele frequency $>0.05$ ) and is likely to tag of the unknown common variants, coding SNPs, 5'-UTR, and 3'-UTR regulatory SNPS were selected based on the JPT (Japanese in Tokyo) and $\mathrm{CHB}$ (Chinese in Beijing) data that were downloaded from the International HapMap site (http://www. hapmap.org) and a public SNP database (http://www. ncbi.nlm.nih.gov/projects/SNP/). To cover the whole RasGRP3 gene by a series of LD blocks, intronic SNPs at regular intervals were selected. 


\section{Genotyping analysis}

Genomic DNA (gDNA) was extracted from whole blood using a commercial gDNA extraction kit (i.e., G-DEX ${ }^{\mathrm{TM}}$ blood genomic DNA purification kit, Intron Biotechnology Inc. Seongnam, Korea). The amount of gDNA was determined using the Picogreen double-strand DNA quantification reagent, according to a standard protocol (Molecular Probes, Eugene, OR). The gDNA was analyzed using a Victor $^{T M} 3$ multilabel counter (with excitation at $480 \mathrm{~nm}$ and emission at $520 \mathrm{~nm}$; PerkinElmer Inc. Waltham, MA), and a standard curve for the concentration of gDNA was created using known concentrations of $\lambda$ DNA. Genotyping was performed using the Golden Gate genotyping assay according to a standard protocol (Illumina, Inc., San Diego, CA, USA). In brief, polymerase chain reactions (PCRs) were performed in reaction mixtures that contained allele-specific extension oligomers and $250 \mathrm{ng}$ of genomic DNA by ramping the temperature from $70^{\circ} \mathrm{C}$ to $30^{\circ} \mathrm{C}$ over a period of 16 hours (Supplementary Table 1). The specific extension products were then used in PCRs that consisted of 34 cycles of 35 seconds at $95^{\circ} \mathrm{C}, 35$ seconds at $56^{\circ} \mathrm{C}$, and 2 minutes at $72^{\circ} \mathrm{C}$. The PCR products were placed in 96-well filter plates (Millipore, Billerica, MA, USA) for purification. Samples were then placed in 384 -well microplates and hybridized at $60^{\circ} \mathrm{C}$ for $30 \mathrm{mi}-$ nutes and at $45^{\circ} \mathrm{C}$ for 16 hours. Finally, the 384-well microplates were washed and scanned at a resolution of 0.8 um using a BeadArray Reader (Illumina, Inc.). Genotyping analysis was performed using Illumina' $s$ Beadstudio software (Version 3). Other reagents were purchased from Sigma-Aldrich (St. Louis, MO).

\section{Statistical analysis}

The $\chi^{2}$ test was used to assess Hardy-Weinberg equilibrium (HWE). Three genetic models (i.e., codominant, dominant, and recessive), proposed by Lewis (Lewis, Cathryn et al. 2002), were used to test for associations between CLD and HCC. LD blocks of 7 SNPs were confirmed using HAPLOVIEW software (version 4.0; http//www.broad.mit.edu/mpg/haploview), according to the confidence interval method. The SNPs were included in an LD block if the MAF exceeded 0.1 and exhibited HWE $(p>0.05)$. Each individual haplotype was inferred using the SAS haplotype procedure. Using a single SNP association test, a haplotype association test, and a diplotype association test, multiple logistic regression models were used to calculate odds ratios (ORs), 95\% confidence intervals (Cls), and corresponding $\mathrm{p}$-values, while controlling for age and gender as covariables. Cox regression models were used to calcu- late hazard ratios (HRs), 95\% Cls, and corresponding $\mathrm{p}$-values, while controlling for gender in the haplotype association test. All statistical tests were performed using SAS software (SAS Enterprise Guide 4.1; SAS Institute, Cary, NC, USA) and HapAnalyzer (Jung, Pack et al., 2004), and results were considered statistically significant if $p$-values were greater than 0.05 .

\section{Results}

The clinical characteristics of the controls (CLD) and cases (HCC) are shown in Table 1. The association between RASGRP3 polymorphisms, CLD, and HCC was evaluated. Two SNPs were identified in the 5'-flanking region (rs597593, rs583942), 2 SNPs were identified in the coding region (rs11680495, rs13388394), 14 SNPs were identified in the intronic region (rs17012996, rs7597095, rs2305577, rs7565568, rs2305573, rs10189430, rs17013236, rs7592762, rs4670191, rs10182807, rs17013337, rs12470399, rs13415927), and 1 SNP was identified in the 3'-untranslated region (UTR; rs1801894) (Supplementary Table 2). Twelve of 19 SNPs were monomorphic or not polymorphic and did not exhibit MAF values less than 0.05 (data not shown). Seven SNPs were identified in the Korean population (Fig. 1A). The LD block was constructed using the confidence interval method in the HAPLOVIEW program (i.e., HWE $>0.05$ and MAF $>0.1, C L D=206, H C C=86$ ) (Fig. 1B). The genotype frequencies of each polymorphism were analyzed in the CLD and HCC groups using logistic regression models (Table 2), while controlling for age and sex as covariates. We identified 2 SNPs (rs7597095, rs7592762)

Table 1. Clinical characteristics of patients with chronic liver disease and hepatocellular carcinoma

\begin{tabular}{lcc}
\hline & $\begin{array}{c}\text { Chronic liver } \\
\text { disease } \\
\text { (CLD) }\end{array}$ & $\begin{array}{c}\text { Hepatocellular } \\
\text { carcinoma } \\
(\mathrm{HCC})\end{array}$ \\
\hline $\mathrm{n}$ & 206 & 86 \\
Gender (M/F) & $158 / 48$ & $69 / 17$ \\
Age (mean \pm SD) & $42.86 \pm 9.62$ & $53.88 \pm 10.58$ \\
HBsAb (Anti-HBs; & 0 & 0 \\
positive rate, \%) & & 37.04 \\
HBeAg (positive rate, \%) & 61.98 & 64.15 \\
HBeAb (Anti-Hbe; & 42.55 & 100 \\
positive rate, \%) & 100 & $117.93 \pm 137.78$ \\
HBsAg (positive rate, \%) & $93.67 \pm 161.74$ & $52.22 \pm 38.80$ \\
AST (U/L, mean $\pm S D)$ & $107.36 \pm 170.25$ & $3.39 \pm 0.69$ \\
ALT (U/L, mean $\pm S D)$ & $3.96 \pm 0.61$ & \\
Albumin (g/dL, & & $2.63 \pm 4.23$ \\
mean \pm SD) & $1.71 \pm 2.88$ & \\
Bilirubin (mg/dL, & & \\
mean \pm SD) & & \\
\hline
\end{tabular}


(A)

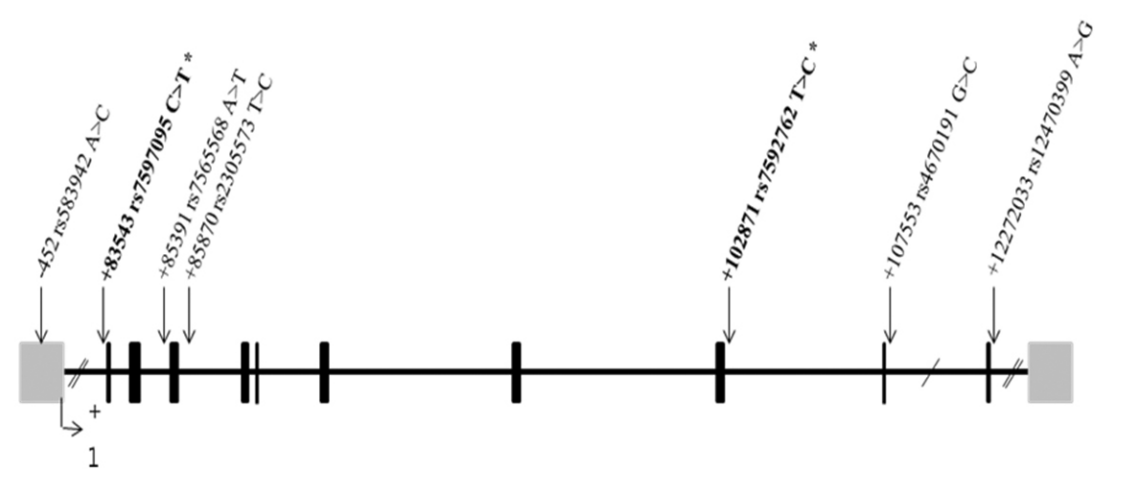

(B)

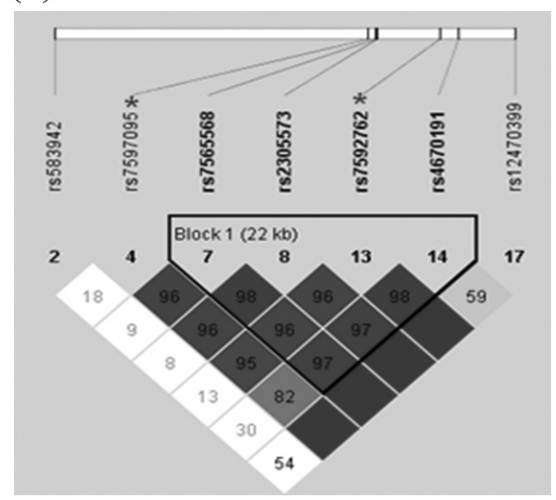

Fig. 1. RasGRP3 gene map, SNPs, and LD. (A) RasGRP3 gene map, indicating the location of 7 SNPs. The 3'- and 5'-UTR are shown as gray boxes, exons are shown as black boxes, and the introns are indicated by lines. The first base of the transcriptional site is denoted as nucleotide +1 . Asterisks indicate significantly associated polymorphisms in CLD and HCC. (B) The 4 SNPs (i.e., rs75655688, rs2305573, rs7592762, rs4670191) were used in the haplotype estimation, and the minor allele frequencies of those SNPs were greater than 0.05 . Asterisks indicate significantly associated polymorphisms in CLD and HCC.

Table 2. Logistic analysis of RasGRP3 gene polymorphisms in the Korean population

\begin{tabular}{|c|c|c|c|c|c|c|c|c|c|c|}
\hline \multirow{2}{*}{ SNP } & \multirow{2}{*}{$\begin{array}{l}\text { Geno- } \\
\text { type }\end{array}$} & \multirow{2}{*}{ egion } & \multirow{2}{*}{ CLD } & \multirow{2}{*}{$\mathrm{HCC}$} & \multicolumn{2}{|c|}{ Codominant } & \multicolumn{2}{|c|}{ Dominant } & \multicolumn{2}{|c|}{ Recessive } \\
\hline & & & & & OR $(95 \% \mathrm{Cl})$ & $p$ & OR $(95 \% \mathrm{Cl})$ & $\mathrm{p}$ & OR $(95 \% \mathrm{Cl})$ & $\mathrm{p}$ \\
\hline \multirow[t]{3}{*}{ rs583942 } & $A A$ & Flanking_5UTR & $112(54.4)$ & $42(48.8)$ & \multirow{3}{*}{$\begin{array}{c}1.204 \\
(0.746 \sim 1.946)\end{array}$} & \multirow{3}{*}{0.447} & \multirow{3}{*}{$\begin{array}{c}1.305 \\
(0.733 \sim 2.323)\end{array}$} & \multirow{3}{*}{0.366} & \multirow{3}{*}{$\begin{array}{c}1.006 \\
(0.279 \sim 3.618)\end{array}$} & \multirow{3}{*}{0.993} \\
\hline & $A C$ & & $82(39.8)$ & $39(45.3)$ & & & & & & \\
\hline & $\mathrm{CC}$ & & $12(5.8)$ & $5(5.8)$ & & & & & & \\
\hline \multirow[t]{3}{*}{ rs7597095 } & $\mathrm{CC}$ & intron & 87 (42.2) & $31(36.0)$ & \multirow{3}{*}{$\begin{array}{c}1.547 \\
(1.012 \sim 2.365)\end{array}$} & \multirow{3}{*}{0.044} & \multirow{3}{*}{$\begin{array}{c}1.790 \\
(0.980 \sim 3.271)\end{array}$} & \multirow{3}{*}{0.058} & \multirow{3}{*}{$\begin{array}{c}1.727 \\
(0.759 \sim 3.933)\end{array}$} & \multirow{3}{*}{0.193} \\
\hline & $\mathrm{CT}$ & & $95(46.1)$ & $42(48.8)$ & & & & & & \\
\hline & $\mathrm{TT}$ & & $24(11.7)$ & $13(15.1)$ & & & & & & \\
\hline \multirow[t]{3}{*}{ rs7565568 } & $A A$ & intron & $110(57.6)$ & $48(55.8)$ & \multirow{3}{*}{$\begin{array}{c}0.867 \\
(0.541 \sim 1.391)\end{array}$} & \multirow{3}{*}{0.554} & \multirow{3}{*}{$\begin{array}{c}0.890 \\
(0.499 \sim 1.587)\end{array}$} & \multirow{3}{*}{0.693} & \multirow{3}{*}{$\begin{array}{c}0.646 \\
(0.184 \sim 2.269)\end{array}$} & \multirow{3}{*}{0.495} \\
\hline & AT & & $81(38.9)$ & $34(39.5)$ & & & & & & \\
\hline & TT & & $15(7.2)$ & $4(4.7)$ & & & & & & \\
\hline \multirow[t]{3}{*}{ rs2305573 } & $\mathrm{TT}$ & intron & $112(53.8)$ & $48(55.8)$ & \multirow{3}{*}{$\begin{array}{c}0.941 \\
(0.588 \sim 1.504)\end{array}$} & \multirow{3}{*}{0.799} & & & & \\
\hline & TC & & $80(26.8)$ & 34 (39.5) & & & $\begin{array}{r}1.004 \\
563 \sim 1790)\end{array}$ & 0.990 & $\begin{array}{c}0.052 \\
(0.18 \sim 2299)\end{array}$ & 0.506 \\
\hline & $\mathrm{CC}$ & & $14(4.7)$ & $4(4.7)$ & & & & & & \\
\hline rs7592762 & $\mathrm{TT}$ & intron & $102(54.3)$ & $33(38.4)$ & & & & & & \\
\hline & TC & & $86(45.7)$ & $41(47.7)$ & 07 & 0.007 & 35 & 0.024 & 2.611 & 0.032 \\
\hline & $\mathrm{CC}$ & & $18(9.5)$ & $12(14.0)$ & & & & & & \\
\hline rs4670191 & GG & intron & $69(33.5)$ & $35(40.7)$ & & & & & & \\
\hline & $\mathrm{GC}$ & & $102(49.5)$ & $37(43.0)$ & $(0501 \sim 1151)$ & 0.195 & $(0325 \sim 10$ & 0.082 & 0.923 & 0.840 \\
\hline & $\mathrm{CC}$ & & $35(17.0)$ & $14(16.3)$ & $(0.50$ & & ) & & & \\
\hline rs12470399 & AA & intron & $161(78.2)$ & $64(74.4)$ & & & & & & \\
\hline & $A G$ & & $41(19.9)$ & $20(23.3)$ & $\begin{array}{l}0.846 \\
61 \sim 1550)\end{array}$ & 0.588 & $(0449 \sim 1765)$ & 0.739 & $(0051 \sim 3354)$ & 0.407 \\
\hline & GG & & $4(1.9)$ & $2(2.3)$ & & & & & & \\
\hline
\end{tabular}

Logistic regression models were used to calculate odds ratios (i.e., 95\% confidence intervals) and corresponding $p$-values for each SNP. p-values obtained using the codominant, dominant and recessive, models are also shown. Age and sex were adjusted in the logistic analysis as covariates. Abbreviations: Freq., frequency; CLD, chronic liver disease; HCC, hepatocellular carcinoma; $95 \% \mathrm{Cl}$, 95\% confidence interval; LCL, lower confidence limit; UCL, upper confidence limit; OR, odds ratio. Bold indicates $\mathrm{p}<0.05$.

that were significantly associated with CLD and HCC. The T allele of the rs7597095 SNP was associated with an increased risk of developing HCC, according to the codominant model (i.e., OR=1.55, 95\% Cl=1.01 2.37, $\mathrm{p}=0.044)$. The $\mathrm{C}$ allele of the rs7592762 SNP was associated with an increased risk of developing HCC, ac- 
cording to the codominant, dominant, and recessive models (i.e., $\mathrm{OR}=1.81 ; 95 \% \mathrm{Cl}=1.17 \sim 2.79 ; \mathrm{p}=0.007$, $\mathrm{OR}=1.97 ; 95 \% \mathrm{Cl}=1.09 \sim 3.56 ; \mathrm{p}=0.024$, OR=2.61;95\% $\mathrm{Cl}=1.09 \sim 6.27 ; \mathrm{p}=0.032$, respectively) (Table 2).

The haplotype frequencies and association test are summarized in Table 3. The 4 RasGRP3 polymorphisms were in an LD (ID'| value, ranging from 0.96 to 0.98 ) block, and we observed 9 haplotypes of a total of 16 haplotypes. Among these haplotypes, 5 had a frequency of less than $1 \%$ and therefore analyzed, except for its haplotypes (data not shown). Of the 4 remaining haplotypes, RasGRP3 ht1 [A-T-C-G] was significantly associated with a risk of developing $\mathrm{HCC}$ in the codominant, dominant, and recessive models (OR=1.79; 95\% $\mathrm{Cl}=1.16 \sim 2.78 ; \mathrm{p}=0.008, \mathrm{OR}=2.78 ; 95 \% \mathrm{Cl}=1.15 \sim 6.67$; $\mathrm{p}=0.024, \quad \mathrm{OR}=1.89 ; 95 \% \mathrm{Cl}=1.05 \sim 3.45 ; \mathrm{p}=0.033$, re- spectively).

We next analyzed the associations between diplotypes of the 4 RasGRP3 haplotypes (i.e., A-T-C-G, A-T-T-C, A-T-T-G, T-C-T-C) and the risk of developing HCC (Table 4). Eighteen distinct diplotypes were identified. Among them, 8 exhibited low frequencies and were not analyzed. When we compared dt1 with dt6 and $\mathrm{dt} 1$ with $\mathrm{dt} 8$, an increased risk of developing HCC was associated with $\mathrm{dt} 1$ (i.e., for $\mathrm{dt} 1 \mathrm{vs}$. $\mathrm{dt} 6, \mathrm{OR}=8.318$, $p=0.009$; and for dt1 vs. $d t 8, O R=3.821, p=0.045$ ). However, dt6 was associated with a decreased risk of developing HCC (i.e., for $\mathrm{dt} 3$ vs. $\mathrm{dt} 6, \mathrm{OR}=4.890$, $p=0.039$; and for dt6 vs. $d t 7, O R=0.189, p=0.046$ ).

A Cox regression model that compared age at disease onset with HCC revealed that RasGRP3 ht1 conferred susceptibility to HCC (i.e., for the codominant

Table 3. Association of the RasGRP3 haplotype with HCC, as determined via logistic regression analysis

\begin{tabular}{|c|c|c|c|c|c|c|c|c|c|}
\hline \multirow{2}{*}{\multicolumn{2}{|c|}{ Haplotype }} & \multirow{2}{*}{ CLD } & \multirow{2}{*}{$\mathrm{HCC}$} & \multicolumn{2}{|l|}{ Codominant } & \multicolumn{2}{|l|}{ Dominant } & \multicolumn{2}{|l|}{ Recessive } \\
\hline & & & & \multirow{2}{*}{$\frac{\mathrm{OR}(95 \% \mathrm{Cl})}{1.79(1.16 \sim 2.78)}$} & \multirow{2}{*}{$\frac{p}{0.008}$} & \multirow{2}{*}{$\frac{\mathrm{OR}(95 \% \mathrm{Cl})}{2.78(1.15 \sim 6.67)}$} & \multirow{2}{*}{$\frac{p}{0.024}$} & \multirow{2}{*}{$\begin{array}{c}\text { OR }(95 \% \mathrm{Cl}) \\
1.89(1.05 \sim 3.45)\end{array}$} & \multirow{2}{*}{$\frac{p}{0.033}$} \\
\hline ht1 & ht1/ht1 & $17(8.25)$ & $12(13.95)$ & & & & & & \\
\hline \multirow[t]{2}{*}{ (A-T-C-G) } & ht1/- & $87(42.23$ & $40(46.51)$ & & & & & & \\
\hline & $-/-$ & $102(49.51)$ & $34(39.53)$ & & & & & & \\
\hline ht2 & ht2/ht2 & $3(1.46)$ & $1(1.16)$ & $0.73(0.40 \sim 1.35)$ & 0.312 & $0.32(0.02 \sim 4.76)$ & 0.406 & $0.75(0.39 \sim 1.45)$ & 0.386 \\
\hline \multirow[t]{2}{*}{ (A-T-T-C) } & ht2/- & $54(26.21)$ & $21(24.42)$ & & & & & & \\
\hline & $-/-$ & $149(72.33)$ & $64(74.42)$ & & & & & & \\
\hline ht3 & ht3/ht3 & $19(9.22)$ & $7(8.14)$ & $0.73(0.47 \sim 1.15)$ & 0.170 & $0.65(0.23 \sim 1.79)$ & 0.402 & $0.68(0.38 \sim 1.20)$ & 0.184 \\
\hline \multirow[t]{2}{*}{ (A-T-T-G) } & ht3/- & $80(38.83)$ & $28(32.56)$ & & & & & & \\
\hline & $-/-$ & $107(51.94)$ & $51(59.30)$ & & & & & & \\
\hline ht4 & ht4/ht4 & $14(6.80)$ & $3(3.49)$ & $0.93(0.58 \sim 1.49)$ & 0.777 & $0.47(0.11 \sim 1.89)$ & 0.285 & $1.05(0.59 \sim 1.89)$ & 0.868 \\
\hline \multirow[t]{2}{*}{ (T-C-T-C) } & ht4/- & $77(37.38)$ & $35(40.70)$ & & & & & & \\
\hline & $-/-$ & $115(55.83)$ & $48(55.81)$ & & & & & & \\
\hline
\end{tabular}

Haplotype association testing was conducted using SAS. Abbreviations: OR, odds ratio; CLD, chronic liver disease; HCC, hepatocellular carcinoma. Bold indicates p-values $<0.05$.

Table 4. Frequencies and association of RasGRP3 diplotype on logistic regression analysis

\begin{tabular}{|c|c|c|c|c|c|c|c|c|c|c|c|c|c|}
\hline \multirow{2}{*}{ Diplotype } & \multicolumn{2}{|c|}{ Number (\%) } & \multicolumn{10}{|c|}{ OR } & \\
\hline & CLD & $\mathrm{HCC}$ & $\mathrm{dt} 1$ & $\mathrm{dt} 2$ & $\mathrm{dt} 3$ & $\mathrm{dt} 4$ & $\mathrm{dt5}$ & dt6 & $\mathrm{dt} 7$ & dt8 & dt9 & $\mathrm{dt} 10$ & \\
\hline dt1 (ht1/ht1) & $17(8.25)$ & 12 (13.95) & & 2.743 & 1.701 & 2.188 & 8.163 & 8.318 & 1.573 & 3.821 & 3.223 & 5.244 & \multirow{10}{*}{ 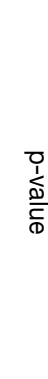 } \\
\hline dt2 (ht1/ht2) & $17(8.25)$ & $8(9.30)$ & 0.136 & & 0.62 & 0.798 & 2.976 & 3.033 & 0.573 & 1.393 & 1.175 & 1.912 & \\
\hline dt3 (ht1/ht3) & $32(15.53)$ & $16(18.60)$ & 0.335 & 0.449 & & 1.286 & 4.799 & 4.89 & 0.925 & 2.246 & 1.895 & 3.083 & \\
\hline dt4 (ht1/ht4) & $34(16.50)$ & $16(18.60)$ & 0.164 & 0.723 & 0.624 & & 3.731 & 3.802 & 0.719 & 1.747 & 1.473 & 2.397 & \\
\hline dt5 (ht2/ht2) & $3(1.46)$ & $1(1.16)$ & 0.153 & 0.463 & 0.277 & 0.363 & & 1.019 & 0.193 & 0.468 & 0.395 & 0.642 & \\
\hline dt6 (ht2/ht3) & $20(9.71)$ & $3(3.49)$ & 0.009 & 0.194 & 0.039 & 0.084 & 0.99 & & 0.189 & 0.459 & 0.388 & 0.631 & \\
\hline dt7 (ht2/ht4) & $16(7.77)$ & $9(10.47)$ & 0.478 & 0.432 & 0.894 & 0.586 & 0.265 & 0.046 & & 2.429 & 2.049 & 3.335 & \\
\hline dt8 (ht3/ht3) & $19(9.22)$ & $7(8.14)$ & 0.045 & 0.648 & 0.194 & 0.374 & 0.608 & 0.358 & 0.205 & & 0.844 & 1.373 & \\
\hline dt9 (ht3/ht4) & $26(12.62)$ & $9(10.47)$ & 0.061 & 0.815 & 0.27 & 0.507 & 0.527 & 0.246 & 0.28 & 0.803 & & 1.627 & \\
\hline $\mathrm{dt} 10(\mathrm{ht} 4 / \mathrm{ht} 4)$ & $14(6.80)$ & $3(3.49)$ & 0.046 & 0.461 & 0.156 & 0.275 & 0.777 & 0.639 & 0.16 & 0.716 & 0.564 & & \\
\hline
\end{tabular}

Abbreviations: OR, odds ratio. Bold indicates p-values $<0.05$. 
Table 5. Cox regression analysis for age of HCC occurrence as a function of haplotype of RasGRP3

\begin{tabular}{|c|c|c|c|c|c|c|c|c|c|}
\hline \multirow{2}{*}{ Type } & \multirow{2}{*}{ Haplotype } & \multirow{2}{*}{ Frequency } & \multirow{2}{*}{ Mean } & \multirow{2}{*}{ SD } & \multirow{2}{*}{ Model } & \multirow{2}{*}{$\mathrm{HR}$} & \multicolumn{2}{|c|}{$95 \% \mathrm{Cl}$} & \multirow{2}{*}{$\mathrm{p}$} \\
\hline & & & & & & & $\mathrm{LCL}$ & UCL & \\
\hline \multirow[t]{3}{*}{ ht1 } & ht1/ht1 & 12 & 48.08 & 11.13 & Co-dominant & 0.662 & 0.474 & 0.924 & 0.015 \\
\hline & ht $1 /-$ & 40 & 54.68 & 10.69 & Dominant & 0.416 & 0.224 & 0.775 & 0.006 \\
\hline & $-/-$ & 34 & 55.00 & 9.89 & Recessive & 0.704 & 0.454 & 1.093 & 0.118 \\
\hline \multirow[t]{3}{*}{ ht2 } & ht2/ht2 & 1 & 69.00 & & Co-dominant & 1.258 & 0.810 & 1.954 & 0.307 \\
\hline & ht2/- & 21 & 55.86 & 11.17 & Dominant & 2.479 & 0.342 & 17.998 & 0.369 \\
\hline & $-/-$ & 64 & 53.00 & 10.29 & Recessive & 1.232 & 0.757 & 2.008 & 0.401 \\
\hline \multirow[t]{3}{*}{ ht3 } & ht3/ht3 & 7 & 55.57 & 10.21 & Co-dominant & 1.189 & 0.853 & 1.657 & 0.308 \\
\hline & ht3/- & 28 & 51.64 & 11.06 & Dominant & 1.361 & 0.626 & 2.960 & 0.436 \\
\hline & $-/-$ & 51 & 54.88 & 10.37 & Recessive & 1.226 & 0.790 & 1.903 & 0.363 \\
\hline \multirow[t]{3}{*}{$\mathrm{ht} 4$} & ht $4 / h t 4$ & 3 & 56.33 & 9.50 & Co-dominant & 1.059 & 0.732 & 1.533 & 0.760 \\
\hline & ht4/- & 35 & 55.60 & 8.95 & Dominant & 1.283 & 0.404 & 4.074 & 0.673 \\
\hline & $-/-$ & 48 & 52.48 & 11.67 & Recessive & 1.041 & 0.678 & 1.598 & 0.855 \\
\hline
\end{tabular}

Cox regression analysis was to calculate hazard ratios, 95\% confidence intervals, and corresponding $p$-values for haplotypes, while controlling for sex. Abbreviations: $95 \% \mathrm{Cl}, 95 \%$ confidence interval; HR, hazard ratios. Bold indicate $\mathrm{p}$-values $<0.05$.

model, mean $\pm \mathrm{STD}=48.08 \pm 11.13, \mathrm{HR}=0.66,95 \% \mathrm{Cl}=$ $0.47 \sim 0.92$, and $p=0.015$; in the dominant model, mean \pm $\mathrm{STD}=54.68 \pm 10.69, \mathrm{HR}=0.42,95 \% \mathrm{Cl}=0.22 \sim 0.78$, and $\mathrm{p}=0.006$ ). Patients who possessed RasGRP3 ht1 developed HCC more quickly than patients who possessed ht-/+ or ht1-/- patients, as indicated by Kaplan-Meier survival curve analysis (Table 5 and Fig. 2). Also, a Cox regression model that compared age at disease onset with HCC revealed that each SNP of RasGRP3 conferred susceptibility to HCC. Patients who had the $\mathrm{C}$ allele of rs7592762 (i.e., for the codominant, mean \pm $\mathrm{STD}=54.91 \pm 10.03, \mathrm{HR}=1.53,95 \% \mathrm{Cl}=1.09 \sim 2.14$, and $\mathrm{p}=0.013$; in the recessive model, mean $\pm \mathrm{STD}=48.03 \pm$ 11.13, $\mathrm{HR}=2.38,95 \% \mathrm{Cl}=1.28 \sim 4.44$, and $\mathrm{p}=0.006$ ) and/or the $\mathrm{C}$ allele of rs4670191 (i.e., for the dominant model, mean $\pm \mathrm{STD}=57.38 \pm 9.38, \mathrm{HR}=0.64,95 \% \mathrm{Cl}=$ $0.41 \sim 0.99$, and $p=0.045)$ developed HCC more quickly than other patients (Supplementary Table 3).

\section{Discussion}

We identified genetic markers that were associated with HCC susceptibility in a Korean population. HCC is the most common type of malignant tumor and the third-most common cause of cancer-related deaths (Bruix, Boix et al., 2004). The progression of human cancers to malignant tumors involves the mutation of genes, such as p53, breast cancer 1 (BRCA1), and Ras, which contribute to cell proliferation, cell cycle progression, apoptosis, and metastasis (Greenblatt, Bennett et al., 1994; Levy-Lahad and Friedman, 2007). Other genes that are involved in Ras signaling regulate various cellular functions, including cell growth, survival, and mi-

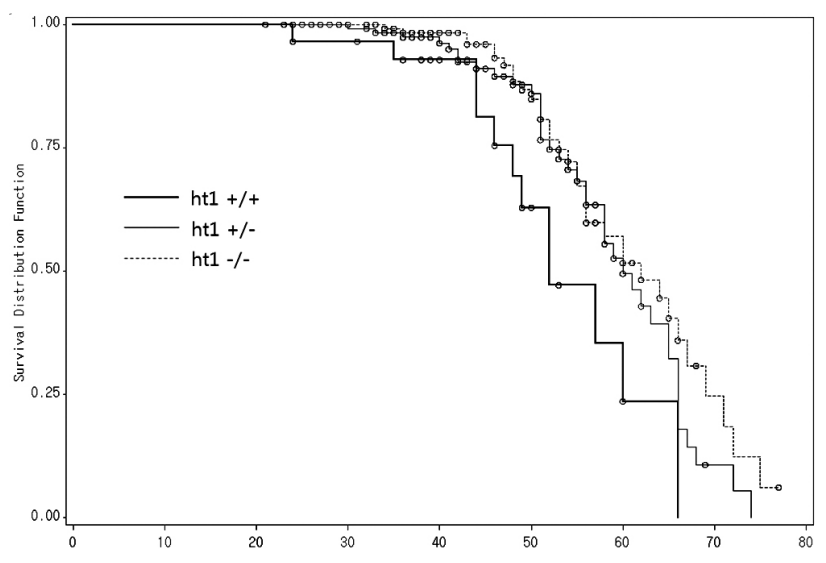

Fig. 2. Kaplan-Meier survival curves for haplotype 1. Plots represent mean-censored data (i.e., in the CLD group).

gration (Vojtek and Der, 1998). Ras genes enhance the metastatic phenotype of the human HCC cell line (Wang, Lin et al., 2001), and Ras proteins are known to be overexpressed in human cirrhotic liver and HCC (Nonomura, Ohta et al., 1987).

Activation of Ras signal transduction pathways depends on RasGRP3, which functions as a GTP/GDP switch. Via the actions of RasGRP3, activated GTP-Ras proteins bind and regulate functionally diverse downstream effectors, such as Ras, Raf1, MEK, and ERK. The RasGRP family is directly associated with the Ras and GTPase molecules (Bar-Sagi and Hall, 2000; Shields, Pruitt et al., 2000), and RasGRP deregulation has been linked to carcinogenesis and tumor progression (Khosravi-Far and Der, 1994). 
The C1 domain of RasGRP3 binds directly to phorbol esters that are potent tumor-promoting operator, thereby increasing the levels of ERK1/ERK2 (Lorenzo, Kung et al., 2001). Also, Rap1 has been reported to be activated by phorbol esters through RasGRP3. RasGRP3-/$B$ cells exhibit undetectable basal levels of Ras-GTP, as well as defective BCR-induced Ras activation, and BCR-induced proliferation in vitro depends on RasGRP3 (Coughlin, Stang et al., 2005; Tangye and Hodgkin, 2004). In addition, RasGRP3 interacts with dynein light chain 1 (DLC1), contributes to cytoskeleton-mediated motility and intracellular transport, and interacts with various proteins that are associated with cell survival and apoptosis (e.g., BimL and IKB $\alpha$ ) (Crepieux, Kwon et al., 1997; Puthalakath, Huang et al., 1999). Thus, RasGRP3 may interact with significant SNPs (i.e., ht1 and dt1), thereby regulating GDP/GTP switches and converting inactive forms to active forms upstream of Ras. These actions also may enhance the expression of Ras and downstream effectors molecules. Our data revealed that patients who possessed the SNPs ht1 or dt1 progressed more quickly to HCC than did other patients (Table 5, Fig. 2).

To our knowledge, this is the first case-control study that demonstrates a significant association between RasGRP3 SNPs and progression from CLD to HCC in a Korean population. Our results show that the $T$ allele of the rs7565568 SNP and the C allele of the rs7592762 SNP increase susceptibility to HCC. Moreover, patients with CLD who possessed ht1 (i.e., A-T-C-G) or dt1 (i.e., A-T-C-G/A-T-C-G) were at increased risk for developing $\mathrm{HCC}$. Finally, we identified an association between ht $1 / \mathrm{ht} 1$ and the age of HCC onset; a highly significant acceleration in HCC progress was apparent among the RasGRP3 ht1-bearing patients.

Thus, our findings suggest significant associations between RasGRP3 SNPs and the development of HCC during HBV infection. In summary, we identified 2 RasGRP3 SNPs (rs7597095, rs7592762), 1 haplotype (ht1; A-T-C-G), and 1 diplotype (dt1; A-T-C-G/A-T-C-G) that were significantly associated with the development of HCC-infected HBV.

\section{Acknowledgments}

We are thankful to every individual who has given us his or her informed consent for this study. This work was supported by grants from the Korean Ministry for Health, Welfare and Family Affairs (A050558), from the Health 21 research and development project of the Korean Ministry for Health, Welfare and Family Affairs (A010383), and from the Korea Research Foundation Grant, funded by the Korean Government (MOEHRD,
Basic Research Promotion Fund) (KRF-2007-511E00037).

\section{References}

Aiba, Y., Oh-hora, M., Kiyonaka, S., Kimura, Y., Hijikata, A., Mori, Y., and Kurosaki, T. (2004). Activation of RasGRP3 by phosphorylation of Thr-133 is required for B cell receptor-mediated Ras activation. Proc. Natl. Acad. Sci. U. S. A. 101, 16612-16617.

Arbuthnot, P., and Kew, M. (2001). Hepatitis B virus and hepatocellular carcinoma. Int. J. Exp. Pathol. 82, 77-100.

Bar-Sagi, D., and Hall, A. (2000). Ras and Rho GTPases: a family reunion. Cell 103, 227-38.

Bosch, F.X., Ribe, J., Diaz, M., and Cleries, R. (2004). Primary liver cancer: worldwide incidence and trends. Gastroenterology 127, S5-S16.

Bruix, J., Boix, L., Sala, M., and Llovet, J.M. (2004). Focus on hepatocellular carcinoma. Cancer Cell 5, 215-219.

Caselmann, W.H. (1998). Pathogenesis of hepatocellular carcinoma. Digestion 59 Suppl 2, 60-63.

Cha, C., and Dematteo, R.P. (2005). Molecular mechanisms in hepatocellular carcinoma development. Best Pract. Res. Clin Gastroenterol 19, 25-37.

Coughlin, J.J., Stang, S.L., Dower, N.A., and Stone, J.C. (2005). RasGRP1 and RasGRP3 regulate B cell proliferation by facilitating $B$ cell receptor-Ras signaling. J. Immunol. 175, 7179-84.

Crepieux, P., Kwon, H., Leclerc, N., Spencer, W., Richard, S., Lin, R., and Hiscott, J. (1997). I kappaB alpha physically interacts with a cytoskeleton-associated protein through its signal response domain. Mol. Cell. Biol. 17, 7375-7385.

Edmondson, H.A., Henderson, B., and Benton, B. (1976). Liver-cell adenomas associated with use of oral contraceptives. N. Engl. J. Med. 294, 470-472.

Greenblatt, M.S., Bennett, W.P., Hollstein, M., and Harris, C.C. (1994). Mutations in the p53 tumor suppressor gene: clues to cancer etiology and molecular pathogenesis. Cancer Res. 54, 4855-4878.

Ito, Y., Sasaki, Y., Horimoto, M., Wada, S., Tanaka, Y., Kasahara, A., Ueki, T., Hirano, T., Yamamoto, H., Fujimoto, J., Okamoto, E., Hayashi, N., and Hori, M. (1998). Activation of mitogen-activated protein kinases/extracellular signal-regulated kinases in human hepatocellular carcinoma. Hepatology 27, 951-958.

Jung, H.Y., Park, J.S., Park, Y.J., Kim, Y.J., Kimm, K.C., and Koh, I.S. (2004). HapAnalyzer: minimum haplotype analysis system for association studies. Genomics \& Informatics 2, 107-109.

Khosravi-Far, R., and Der, C.J. (1994). The Ras signal transduction pathway. Cancer Metastasis Rev. 13, 67-89.

Kirk, G.D., Lesi, O.A., Mendy, M., Szymanska, K., Whittle, H., Goedert, J.J., Hainaut, P., and Montesano, R. (2005). 249(ser) TP53 mutation in plasma DNA, hepatitis B viral infection, and risk of hepatocellular carcinoma. Oncogene 24, 5858-5867.

Laurent-Puig, P., and Zucman-Rossi, J. (2006). Genetics of hepatocellular tumors. Oncogene 25, 3778-3786. 
Levy-Lahad, E., and Friedman, E. (2007). Cancer risks among BRCA1 and BRCA2 mutation carriers. $\mathrm{Br}$. J. Cancer 96, 11-15.

Lewis, C.M. (2002). Genetic association studies: design, analysis and interpretation. Brief Bioinform 3, 146-153.

Lee, S.K., Kim, H.G., Kang, J.J., Oh, W., Oh, B.E., and Kwack, K. (2007). Characterization of single nucleotide polymorphisms in 55disease-associated genes in a Korean population. Genomics \& informatics 5, 152-160.

Lorenzo, P.S., Kung, J.W., Bottorff, D.A., Garfield, S.H., Stone, J.C., and Blumberg, P.M. (2001). Phorbol esters modulate the Ras exchange factor RasGRP3. Cancer Res, 61, 943-9.

Mitin, N., Rossman, K.L., and Der, C.J. (2005). Signaling interplay in Ras superfamily function. Curr. Biol. 15(14), R563-R574.

Nonomura, A., Ohta, G., Hayashi, M., Izumi, R., Watanabe,

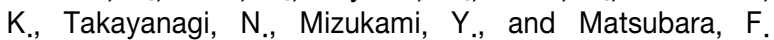
(1987). Immunohistochemical detection of ras oncogene p21 product in liver cirrhosis and hepatocellular carcinoma. Am. J. Gastroenterol. 82, 512-518.

Pang, R., Yuen, J., Yuen, M.F., Lai, C.L., Lee, T.K., Man, K., Poon, R.T., Fan, S.T., Wong, C.M., Ng, I.O., Kwong, Y.L., and Tse, E. (2004). PIN1 overexpression and beta-catenin gene mutations are distinct oncogenic events in human hepatocellular carcinoma. Oncogene 23, 41824186.

Park, B.L., Kim, Y.J., Cheong, H.S., Lee, S.O., Han, C.S., Yoon, J.H., Park, J.H., Chang, H.S., Park, C.S., Lee, H.S., and Shin, H.D. (2007). HDAC10 promoter polymorphism associated with development of HCC among chronic HBV patients. Biochem. Biophys, Res, Commun. 363, 776-781.

Parkin, D.M., Bray, F., Ferlay, J., and Pisani, P. (2001). Estimating the world cancer burden: Globocan 2000. Int. J. Cancer 94, 153-156.

Puthalakath, H., Huang, D.C., O'Reilly, L.A., King, S.M., and Strasser, A. (1999). The proapoptotic activity of the Bcl-2 family member Bim is regulated by interaction with the dynein motor complex. Mol. Cell. 3, 287-296.

Rebhun, J.F., Castro, A.F., and Quilliam, L.A. (2000). Identification of guanine nucleotide exchange factors (GEFs) for the Rap1 GTPase. Regulation of MR-GEF by M-Ras-GTP interaction. J. Biol. Chem. 275, 34901-34908.

Roberts, D.M., Anderson, A.L., Hidaka, M., Swetenburg, R.L., Patterson, C., Stanford, W.L., and Bautch, V.L. (2004). A vascular gene trap screen defines RasGRP3 as an angiogenesis-regulated gene required for the endothelial response to phorbol esters. Mol. Cell. Biol. 24, 10515-10528.

Schmidt, C.M., McKillop, I.H., Cahill, P.A., and Sitzmann, J.V. (1997). Increased MAPK expression and activity in primary human hepatocellular carcinoma. Biochem Biophys. Res. Commun. 236, 54-58.

Shields, J.M., Pruitt, K., McFall, A., Shaub, A., and Der, C.J. (2000). Understanding Ras: 'it ain't over 'til it's over'. Trends Cell Biol. 10, 147-154.

Tangye, S.G., and Hodgkin, P.D. (2004). Divide and conquer: the importance of cell division in regulating $\mathrm{B}$-cell responses. Immunology 112, 509-520.

Tsuboi, Y., Ichida, T., Sugitani, S., Genda, T., Inayoshi, J., Takamura, M., Matsuda, Y., Nomoto, M., and Aoyagi, Y. (2004). Overexpression of extracellular signal-regulated protein kinase and its correlation with proliferation in human hepatocellular carcinoma. Liver Int. 24, 432-436.

Vojtek, A.B., and Der, C.J. (1998). Increasing complexity of the Ras signaling pathway. J. Biol. Chem. 273, 1992519928.

Wang, Q., Lin, Z.Y., and Feng, X.L. (2001). Alterations in metastatic properties of hepatocellular carcinoma cell following $\mathrm{H}$-ras oncogene transfection. World J. Gastroenterol. 7, 335-339.

Wu, L.M., Zhang, F., Xie, H.Y., Xu, X., Chen, Q.X., Yin, S.Y., Liu, X.C., Zhou, L., Xu, X.B., Sun, Y.L., and Zheng, S.S. (2008). MMP2 promoter polymorphism (C-1306T) and risk of recurrence in patients with hepatocellular carcinoma after transplantation. Clin. Genet. 73, 273-278. 
Supplementary Table 1. Primer sequence information of each SNP for genotyping

\begin{tabular}{|c|c|c|c|}
\hline SNP & Universal PCR sequence 1 & Universal PCR sequence 2 & Universal PCR sequence 3 \\
\hline \multirow[t]{2}{*}{ rs597593 } & ACTTCGTCAGTAACGGACAAAATCTACT & GAGTCGAGGTCATATCGTAAAATCTACT & ATATTAATAAACATGCACACAAAGTATCA \\
\hline & CTTAAATTCCTTTTTTGAAGA & CTTAAATTCCTTTTTGAAGG & $\begin{array}{l}\text { GTCGTGCGATGTTCCAAGCGTCTGCCTA } \\
\text { TAGTGAGTC }\end{array}$ \\
\hline \multirow[t]{2}{*}{ rs583942 } & ACTTCGTCAGTAACGGACGCAAATATTA & GAGTCGAGGTCATATCGTGCAAATATTA & AAACATTAATTTTAAAGACAATTTTTGGCC \\
\hline & TACTGTGTATGCCATGCTTTA & TACTGTGTATGCCATGCTTTC & $\begin{array}{l}\text { CGGCATAATACAGTCCTACGTCTGCCTA } \\
\text { TAGTGAGTC }\end{array}$ \\
\hline \multirow[t]{2}{*}{ rs17012996 } & ACTTCGTCAGTAACGGACTCTCCTCACC & GAGTCGAGGTCATATCGTTCTCCTCACC & GCATCCTTCTTCAATGTCTTCTCGCCCA \\
\hline & TTCTGGTCAATGAA & TTCTGGTCAATGAG & $\begin{array}{l}\text { GTTGATGGAGAGCGTAGTCTGCCTATAG } \\
\text { TGAGTC }\end{array}$ \\
\hline \multirow[t]{2}{*}{ rs7597095 } & ACTTCGTCAGTAACGGACGCTTTGCACA & GAGTCGAGGTCATATCGTGCTTTGCACA & GCCCTCAATGTATACCAATTCCATGTAT \\
\hline & СCCCTGCAGCTA & CCСCTGCAGCTG & $\begin{array}{l}\text { GACGGCTCCTTATGTGGGTCTGCCTATA } \\
\text { GTGAGTC }\end{array}$ \\
\hline \multirow[t]{2}{*}{ rs2305577 } & ACTTCGTCAGTAACGGACGGGTGGGAG & GAGTCGAGGTCATATCGTGGGTGGGAG & TGTTGTCAAACTAGGTCTGCATTTCTGTA \\
\hline & GGGTATCAGAGTAGAGT & GGGTATCAGAGTAGAGC & $\begin{array}{l}\text { GCATCGAATCAGTGGAGTCTGCCTATAG } \\
\text { TGAGTC }\end{array}$ \\
\hline \multirow[t]{2}{*}{ rs11680495 } & ACTTCGTCAGTAACGGACGCGTATGACT & GAGTCGAGGTCATATCGTGCGTATGACT & GCTAGTCAACTAGGATATGAAAAATGAC \\
\hline & GAGGAATTTCGGGAAGT & GAGGAATTTCGGGAAGC & $\begin{array}{l}\text { CTCAAGGAAGCGGCGATTGTCTGCCTAT } \\
\text { AGTGAGTC }\end{array}$ \\
\hline \multirow[t]{2}{*}{ rs7565568 } & ACTTCGTCAGTAACGGACGCAGACAGG & GAGTCGAGGTCATATCGTGCAGACAGG & CATCCAGAATTTCTTACTTAGTGTCATCA \\
\hline & GTAGGTTTTGCACTGAA & GTAGGTTTTGCACTGAT & $\begin{array}{l}\text { ACCTATTCTGCGGCAAAGGGGTCTGCC } \\
\text { TATAGTGAGTC }\end{array}$ \\
\hline \multirow[t]{2}{*}{ rs2305573 } & ACTTCGTCAGTAACGGACCTTCTATCAC & GAGTCGAGGTCATATCGTCTTCTATCAC & AGTGCCCTTAATTCACAGGAGACAGCAA \\
\hline & TGTGCTCTGCTGGAA & TGTGCTCT & $\begin{array}{l}\text { CTTGGGCTCCGGTTGTCTGCCTATAGTG } \\
\text { AGTC }\end{array}$ \\
\hline \multirow[t]{2}{*}{ rs10189430 } & ACTTCGTCAGTAACGGACGCAAACAACT & GAGTCGAGGTCATATC & CAATGTGTGGCTAGGAAATTCCGTAAAC \\
\hline & TTCССТССТGCACAA & TTCССTСCTGCACAC & $\begin{array}{l}\text { TGTAGACCGCCTTGTCGTCTGCCTATAG } \\
\text { TGAGTC }\end{array}$ \\
\hline \multirow[t]{2}{*}{ rs7605981 } & ACTTCGTCAGTAACGGACAGCAGCTCC & GAGTCGAGGTCATATCGTAGCAGCTCC & CTGAGTCACGGATGAGGGATATCGACTT \\
\hline & CAGGTGCTCAGT & CAGGTGCTCAGG & $\begin{array}{l}\text { TGTAGCAGCCGAGGTTGTCTGCCTATAG } \\
\text { TGAGTC }\end{array}$ \\
\hline \multirow[t]{2}{*}{ rs17013236 } & ACTTCGTCAGTAACGGACC & GAGTCGAGGTCATATCGTGGGAAAGCT & TAAAAATGTCGGATTACATTTATTTGCGA \\
\hline & ACAACAAAATTAGAAGGG & ACAACAAAATTAGAAGGC & $\begin{array}{l}\text { AACCACGTCATACTTGCACGTCTGCCTA } \\
\text { TAGTGAGTC }\end{array}$ \\
\hline \multirow{2}{*}{ rs13388394 } & ACTTCGTCAGTAA & CCGTGACAGGCTT & GTAGGCTGCTGATAAACAAAAATACACG \\
\hline & GTTGGGCGTCGT & GTTGGGCGTCGC & $\begin{array}{l}\text { TTGCCCTTAGGTATCCGGTCTGCCTATA } \\
\text { GTGAGTC }\end{array}$ \\
\hline \multirow[t]{2}{*}{ rs7592762 } & ACTTCGTCAGTAACGGACTGCCCTCTCT & GAGTCGAGGTCATATCGTTGCCCTCTCT & САСТTАССТССАСТААТТTССТTGСТGTА \\
\hline & ТТАТТСТСССТСАА & TTATTCT & $\begin{array}{l}\text { TTCACCACCGTGGCTAGTCTGCCTATAG } \\
\text { TGAGTC }\end{array}$ \\
\hline \multirow[t]{2}{*}{ rs4670191 } & ACTTCGTCAGTAACGGAC & GAGTCGAGGTCATATCGT & TAAGCAATAGAAGCAATATAGCAATCCG \\
\hline & ATTTTTTGAGGTTGAGAC & ATTTTTTGAGGTTGAGAG & $\begin{array}{l}\text { TTGCAGTAGGTGACATATCCGTCTGCCT } \\
\text { ATAGTGAGTC }\end{array}$ \\
\hline \multirow[t]{2}{*}{ rs10182807 } & ACTTCGTCAGTAACGGACGTGGCTCTGA & GAGTCGAGGTCATATCGTGTGGCTCTGA & AAACTCATGTTATCACCACAGCGGCATT \\
\hline & GAAAGAAAAGGGAAAC & GAAAGAAAAGGGAAAG & $\begin{array}{l}\text { TCGTGTACCTACCACCGTCTGCCTATAG } \\
\text { TGAGTC }\end{array}$ \\
\hline \multirow[t]{2}{*}{ rs17013337 } & ACTTCGTCAGTAACGGACGTGCACTTGC & GAGTCGAGGTCATATCGTGTGCACTTGC & AAAATTCTCTTAGATTTGCTCAGACTCTG \\
\hline & СTTCCTGAGGTTCT & CTTCCTGAGGTTCC & $\begin{array}{l}\text { TGAGCGTTATCGACCCGTCTGCCTATAG } \\
\text { TGAGTC }\end{array}$ \\
\hline \multirow[t]{2}{*}{ rs12470399 } & ACTTCGTCAGTAACGGACGCAACCCAC & GAGTCGAGGTCATATCGTGCAACCCAC & GAGGCTGAAAGTGCTGAGATACAAACC \\
\hline & AAAGAAAACCAGAAGAA & AAAGAAAACCAGAAGAG & $\begin{array}{l}\text { GTGTAGGATTGGCCTCGTCTGCCTATAG } \\
\text { TGAGTC }\end{array}$ \\
\hline \multirow[t]{2}{*}{ rs13415927 } & ACTTCGTCAGTAACGGACGTGTTATATG & GAGTCGAGGTCATATCGTGTGTTATATG & AGGTTCCAATTTGTGTTTCAGTGGACGT \\
\hline & AGATCCAGCCATGCAA & AGATCCAGCCATGCAG & $\begin{array}{l}\text { GCATGATAAGCTCCCGTCTGCCTATAGT } \\
\text { GAGTC }\end{array}$ \\
\hline \multirow{2}{*}{ rs1801894 } & ACTTCGTCAGTAACGGACGGAAAAATAG & GAGTCGAGGTCATATCGTGGAAAAATAG & GAATGACAGGAATGATCTATTACCATCA \\
\hline & AGCTGGGACTGAGCCTT & AGCTGGGACTGAGCCTG & $\begin{array}{l}\text { AATGCGGTCTCTAGTTACGGGTCTGCCT } \\
\text { ATAGTGAGTC }\end{array}$ \\
\hline
\end{tabular}


190 Genomics \& Informatics Vol. 6(4) 181-191, December 2008

Supplementary Table 2. Logistic analysis of 19 SNPs of the RasGRP3 gene in a Korean population

\begin{tabular}{|c|c|c|c|c|c|c|c|c|}
\hline \multirow{2}{*}{ rs } & \multirow{2}{*}{ Genotype } & \multirow{2}{*}{ Function } & \multicolumn{2}{|l|}{ Co } & \multicolumn{2}{|l|}{ Do } & \multicolumn{2}{|l|}{$\mathrm{Re}$} \\
\hline & & & OR $(95 \% \mathrm{Cl})$ & $\mathrm{p}$ & OR $(95 \% \mathrm{Cl})$ & $\mathrm{p}$ & OR $(95 \% \mathrm{Cl})$ & $\mathrm{p}$ \\
\hline \multirow[t]{3}{*}{ rs597593 } & TT & Flanking_5UTR & $1.616(0.822 \sim 3.178)$ & 0.164 & $1.509(0.694 \sim 3.279)$ & 0.299 & $1.651(0.731 \sim 3.729)$ & 0.228 \\
\hline & $\mathrm{TC}$ & & & & & & & \\
\hline & $\mathrm{CC}$ & & & & & & & \\
\hline \multirow[t]{3}{*}{ rs583942 } & AA & Flanking_5UTR & $1.204(0.746 \sim 1.946)$ & 0.491 & $1.305(0.733 \sim 2.323)$ & 0.447 & $1.006(0.279 \sim 3.618)$ & 0.366 \\
\hline & $A C$ & & & & & & & \\
\hline & $\mathrm{CC}$ & & & & & & & \\
\hline \multirow[t]{2}{*}{ rs17012996 } & AA & Intron & $4.231(0.702 \sim 25.520)$ & 0.116 & $4.231(0.702 \sim 25.520)$ & 0.116 & & \\
\hline & $A G$ & & & & & & & \\
\hline \multirow[t]{3}{*}{ rs7597095 } & $\mathrm{CC}$ & Intron & $1.547(1.012 \sim 2.365)$ & 0.044 & $1.790(0.980 \sim 3.271)$ & 0.058 & $1.727(0.759 \sim 3.933)$ & 0.193 \\
\hline & CT & & & & & & & \\
\hline & $\mathrm{TT}$ & & & & & & & \\
\hline \multirow[t]{3}{*}{ rs2305577 } & $\mathrm{TT}$ & Intron & $0.746(0.280 \sim 1.986)$ & 0.558 & $0.746(0.280 \sim 1.986)$ & 0.558 & & \\
\hline & TC & & & & & & & \\
\hline & $\mathrm{CC}$ & & & & & & & \\
\hline rs11680495 & $\mathrm{TT}$ & Coding & & & & & & \\
\hline \multirow[t]{3}{*}{ rs7565568 } & AA & Intron & $0.867(0.541 \sim 1.391)$ & 0.554 & $0.890(0.499 \sim 1.587)$ & 0.693 & $0.646(0.184 \sim 2.269)$ & 0.495 \\
\hline & AT & & & & & & & \\
\hline & $\mathrm{TT}$ & & & & & & & \\
\hline \multirow[t]{3}{*}{ rs2305573 } & $\mathrm{TT}$ & Intron & $0.941(0.588 \sim 1.504)$ & 0.799 & $1.004(0.563 \sim 1.790)$ & 0.990 & $0.652(0.185 \sim 2.299)$ & 0.506 \\
\hline & $\mathrm{TC}$ & & & & & & & \\
\hline & $\mathrm{CC}$ & & & & & & & \\
\hline \multirow[t]{2}{*}{ rs10189430 } & GG & Intron & & & & & & \\
\hline & GT & & & & & & & \\
\hline \multirow[t]{2}{*}{ rs7605981 } & AA & Intron & & & & & & \\
\hline & $A C$ & & & & & & & \\
\hline rs17013236 & $\mathrm{CC}$ & Intron & & & & & & \\
\hline \multirow[t]{2}{*}{ rs13388394 } & AA & Coding & & & & & & \\
\hline & $A G$ & & & & & & & \\
\hline \multirow[t]{3}{*}{ rs7592762 } & $\mathrm{TT}$ & Intron & $1.806(1.171 \sim 2.786)$ & 0.007 & $1.972(1.091 \sim 3.564)$ & 0.024 & $2.611(1.086 \sim 6.274)$ & 0.032 \\
\hline & $\mathrm{TC}$ & & & & & & & \\
\hline & $\mathrm{CC}$ & & & & & & & \\
\hline \multirow[t]{3}{*}{ rs4670191 } & $G G$ & Intron & $0.759(0.501 \sim 1.151)$ & 0.195 & $0.590(0.325 \sim 1.070)$ & 0.082 & $0.923(0.425 \sim 2.003)$ & 0.840 \\
\hline & $\mathrm{GC}$ & & & & & & & \\
\hline & $\mathrm{CC}$ & & & & & & & \\
\hline rs10182807 & GG & Intron & & & & & & \\
\hline \multirow[t]{2}{*}{ rs 17013337} & GG & Intron & $0.286(0.034 \sim 2.427)$ & 0.252 & $0.286(0.034 \sim 2.427)$ & 0.252 & & \\
\hline & GA & & & & & & & \\
\hline \multirow[t]{3}{*}{ rs12470399 } & AA & Intron & $0.846(0.461 \sim 1.550)$ & 0.588 & $0.890(0.449 \sim 1.765)$ & 0.739 & $0.412(0.051 \sim 3.354)$ & 0.407 \\
\hline & $A G$ & & & & & & & \\
\hline & $G G$ & & & & & & & \\
\hline \multirow[t]{3}{*}{ rs13415927 } & AA & Intron & $3.934(1.746 \sim 8.864)$ & 0.001 & $3.784(1.606 \sim 8.920)$ & 0.002 & & \\
\hline & $A G$ & & & & & & & \\
\hline & GG & & & & & & & \\
\hline rs1801894 & $G G$ & 3UTR & & & & & & \\
\hline
\end{tabular}

Logistic regression models were used to calculate odds ratios (i.e., 95\% confidence intervals) and corresponding p-values for each SNP. p-values obtained using the codominant, dominant,and recessive models are also shown. Age and sex were adjusted in the logistic analysis as covariates. Abbreviations: Freq., frequency; CLD, chronic liver disease; HCC, hepatocellular carcinoma; $95 \% \mathrm{Cl}, 95 \%$ confidence interval; LCL, lower confidence limit; UCL, upper confidence limit OR, odds ratio. Boldindicates $p<0.05$. 
Supplementary Table 3. Cox regression analysis for age of HCC occurrence as a function of each SNP of RasGRP3

\begin{tabular}{|c|c|c|c|c|c|c|c|c|c|c|}
\hline \multirow{2}{*}{ SNP } & \multirow{2}{*}{ Region } & \multirow{2}{*}{ Genotype } & \multirow{2}{*}{ Frequency } & \multirow{2}{*}{ Mean } & \multirow{2}{*}{ SD } & \multirow{2}{*}{ Model } & \multirow{2}{*}{$\mathrm{HR}$} & \multicolumn{2}{|c|}{$95 \% \mathrm{Cl}$} & \multirow{2}{*}{$p$-val } \\
\hline & & & & & & & & $\mathrm{LCL}$ & UCL & \\
\hline \multirow[t]{3}{*}{ rs583942 } & Flanking_5UTR & AA & 42 & 53.93 & 11.65 & Co-dominant & 1.077 & 0.763 & 1.52 & 0.674 \\
\hline & & $A C$ & 39 & 53.51 & 9.96 & Dominant & 1.134 & 0.739 & 1.739 & 0.565 \\
\hline & & $\mathrm{CC}$ & 5 & 56.4 & 6.19 & Recessive & 0.943 & 0.38 & 2.34 & 0.900 \\
\hline \multirow[t]{3}{*}{ rs7597095 } & Intron & $\mathrm{CC}$ & 31 & 55.74 & 9.7 & Co-dominant & 1.327 & 0.978 & 1.801 & 0.069 \\
\hline & & $\mathrm{CT}$ & 42 & 53.52 & 10.48 & Dominant & 1.494 & 0.954 & 2.34 & 0.080 \\
\hline & & $\mathrm{TT}$ & 13 & 50.62 & 12.72 & Recessive & 1.398 & 0.771 & 2.537 & 0.270 \\
\hline \multirow[t]{3}{*}{ rs7565568 } & Intron & $A A$ & 48 & 52.48 & 11.67 & Co-dominant & 0.917 & 0.634 & 1.325 & 0.644 \\
\hline & & AT & 34 & 55.76 & 9.03 & Dominant & 0.889 & 0.58 & 1.364 & 0.590 \\
\hline & & $\mathrm{TT}$ & 4 & 54.75 & 8.38 & Recessive & 0.995 & 0.363 & 2.726 & 0.992 \\
\hline \multirow{3}{*}{ rs2305573 } & Intron & $\mathrm{TT}$ & 48 & 52.48 & 11.67 & Co-dominant & 0.965 & 0.67 & 1.391 & 0.849 \\
\hline & & $\mathrm{TC}$ & 34 & 55.76 & 9.03 & Dominant & 0.953 & 0.621 & 1.463 & 0.825 \\
\hline & & $\mathrm{CC}$ & 4 & 54.75 & 8.38 & Recessive & 0.996 & 0.363 & 2.729 & 0.994 \\
\hline \multirow[t]{3}{*}{ rs7592762 } & Intron & $\mathrm{TT}$ & 33 & 54.91 & 10.03 & Co-dominant & 1.527 & 1.092 & 2.136 & 0.013 \\
\hline & & $\mathrm{TC}$ & 41 & 54.76 & 10.57 & Dominant & 1.445 & 0.929 & 2.249 & 0.103 \\
\hline & & $\mathrm{CC}$ & 12 & 48.08 & 11.13 & Recessive & 2.383 & 1.28 & 4.437 & 0.006 \\
\hline \multirow[t]{3}{*}{ rs4670191 } & Intron & $G G$ & 35 & 49.89 & 10.87 & Co-dominant & 0.804 & 0.581 & 1.114 & 0.190 \\
\hline & & GC & 37 & 57.38 & 9.38 & Dominant & 0.64 & 0.414 & 0.99 & 0.045 \\
\hline & & $\mathrm{CC}$ & 14 & 54.64 & 10.07 & Recessive & 1.05 & 0.587 & 1.878 & 0.870 \\
\hline \multirow[t]{3}{*}{ rs12470399 } & Intron & AA & 64 & 52.55 & 10.64 & Co-dominant & 0.708 & 0.462 & 1.085 & 0.113 \\
\hline & & $A G$ & 20 & 56.35 & 8.83 & Dominant & 0.711 & 0.429 & 1.177 & 0.184 \\
\hline & & $\mathrm{GG}$ & 2 & 72 & 4.24 & Recessive & 0.383 & 0.092 & 1.598 & 0.188 \\
\hline \multirow[t]{3}{*}{ rs13415927 } & Intron & AA & 69 & 54.3 & 10.08 & Co-dominant & 1.564 & 0.924 & 2.648 & 0.096 \\
\hline & & $A G$ & 16 & 53.25 & 12.23 & Dominant & 1.459 & 0.851 & 2.502 & 0.170 \\
\hline & & $G G$ & 1 & 35 & & Recessive & 60.667 & 6.771 & 543.573 & 0.0002 \\
\hline
\end{tabular}

Cox regression analysis wasto calculate hazard ratios, 95\% confidence intervals and corresponding p-values for SNPs, while controlling for sex. Abbreviations: $95 \% \mathrm{Cl}, 95 \%$ confidence interval; HR, hazard ratios. Bold indicates $\mathrm{p}$-values $<0.05$. 